\title{
КУЛЬТУРНЫЕ И ЛИЧНОСТНЫЕ ДЕТЕРМИНАНТЫ СТРАТЕГИИ ПРИНЯТИЯ ЭКОНОМИЧЕСКИХ РЕШЕНИЙ
}

\author{
И. С. Шавкунова \\ Байкальский государственный университет, г. Иркутск, Российская Федерациия
}

\section{ИНФОРМАЦИЯ О СТАТЬЕ}

Дата поступления

9 октября 2017 г.

Дата принятия к печати 11 декабря 2017 г.

Дата онлайн-размещения 27 декабря 2017 г.

\section{КАЮЧЕВЫЕ СЛОВА}

Экономическое решение, стратегия принятия решений, культурные и личностные детерминанты стратегии принятия экономического решения

\begin{abstract}
АННОТАЦИЯ
Развитие общества, в том числе, социально-экономическое, в значительной мере обусловлено культурными и личностными детерминантами, понимаемыми в широком смысле и включающими накопленный на различных этапах исторического развития опыт (индивидуальный и коллективный), доминирующее в обществе мировоззрение, в том числе религиозное и т.д. Изучение культурных и личностных детерминант стратегии принятия субъектом решений, в том числе экономических относится к числу важнейших направлений исследований современной психологии и экономической теории. Актуальность исследования культурных и личностных детерминант стратегии принятия экономических решений обусловлена ролью, которую экономические решения, принимаемые человеком или группой лиц, играют в организации хозяйственной деятельности, как самого человека, отдельных социальных групп, так и общества в целом. Экономическое благополучие человека и общества в целом определяется тем, какие конкретно экономические решения будут приняты людьми в каждый момент времени. Кроме того, существует определенное противоречие между доминирующими в науке представлениями о рациональной природе экономических решений и социокультурными, личностными его детерминантами, что также определяет необходимость определения характера и степени их влияния на стратегию принятия экономических решений. Представлен анализ основных культурных и личностных детерминант стратегии принятия экономических решений, их взаимосвязи и взаимообусловленности. Анализ культурных и личностных детерминант стратегии принятия экономических решений носит междисциплинарный характер, интегрируя психологические и экономические подходы. Практическая значимость изучения культурных и личностных детерминант стратегии принятия экономических решений заключается в возможности применения полученных результатов для прогнозирования характера принимаемых субъектом экономических решений, а также для моделирования программ по формированию компетентности в принятии экономических решений.
\end{abstract}

\section{CULTURAL AND PERSONAL DETERMINANTS OF ECONOMIC DECISIONS-MAKING STRATEGY}

Irina S. Shavkunova

Baikal State University, Irkutsk, Russian Federation

\section{ARTICLE INFO}

Received

October 9, 2017

Accepted

December 11, 2017

Available online December 27, 2017

\begin{abstract}
The development of society, including socio-economic aspect, was largely determined by cultural and personal determinants understood in a broad sense and includes accumulated experience at different stages of historical development (individual and collective), the dominant worldview of the society, including religious, etc. The study of the cultural and personal determinants of decisionsmaking strategy of a person (including economic ones) is among the most important areas of research of modern psychology and economic theory. The relevance of the study of cultural and personal determinants of economic decision-making strategy is conditioned by the role that the economic decisions of a person or group of persons plays in the organization of economic activity of the person, separate social groups, and the society as a whole. The economic welfare of individuals and society is determined by the specific economic decisions that are taken by people at every specific time. In addition, there is a certain contradic-
\end{abstract}




\section{KEYWORDS}

Economic decision, decisionmaking strategy, cultural and personal determinants of economic decision-making strategy tion between the dominant science ideas about the rational nature of economic decisions and socio-cultural and personal determinants that also determine the necessity of specifying the nature and the scale of their influence on the economic decision-making strategy. The author presents an analysis of the main cultural and personal determinants of economic decision-making strategy, their interrelationship and interdependence that is of interdisciplinary nature integrating psychological and economic approaches. The practical significance of the study lies in the possibility of applying the results to predict the nature of taken economic decisions taken, as well as for modeling the development of competence in economic decision-making.
Большое значение для понимания механизма принятия экономических решений, особенностей формирования стратегии принятия экономических решений человеком или группой лиц имеет определение факторов, оказывающих влияние на процесс их формирования и принятия. Характер выбора, особенности принятия экономических решений во многом определяются как личностью лица, принимающего решения и его психологическими особенностями, так и объективными условиями, в которых находиться лицо, принимающее решение. Все многообразие факторов, влияющих на процесс выбора и принятия экономических решений, можно условно разделить на две группы:

объективные (ситуационные) факторы социально-исторические, культурные факторы;

субъективные факторы - личностные (психологические) характеристики человека.

В процессе принятия решений наиболее явно проявляются специфика восприятия, интерпретации, переработки информации лицом, принимающим решение, которые, в свою очередь, непосредственно зависят от культурных и личностных характеристик человека. Кросс-культурные исследования и межкультурный опыт взаимодействия показывают, что люди в процессе принятия экономических решений ведут себя по-разному в зависимости от принадлежности к определенной культуре.

Культура определяется как специфический способ организации и развития человеческой жизнедеятельности, представленный в продуктах материального и духовного труда, в системе социальных норм и учреждений, в духовных ценностях, в совокупности взаимоотношений людей к себе самим, между собой и с природой ${ }^{1}$. Это набор установок, ценностей, представлений и моделей поведе-

\footnotetext{
${ }^{1}$ Вайнер Э. Н., Кастюнин С. А. Адаптивная физическая культура : крат. энцикл. слов. М., 2003. 144 с.
}

ния, разделяемых группой людей и передающихся из поколения в поколение. Культура характеризует особенности поведения и сознания человека в конкретных условиях общественной жизни, оказывает влияние на стадии осознания потребности, поиска и оценки альтернативных вариантов выбора. Решение, в особенности экономическое, является во многом результатом оценки ситуации путем обработки информации, и культура, оказывая влияние на процесс поиска и осмысления информации, тем самым непосредственно воздействует на процесс принятия решения. Представители различных культур имеют специфические представления о благополучии и благосостоянии. Иерархия ценностей и формы приемлемого поведения, религиозные и мировоззренческие убеждения, отношение к власти, половозрастные стереотипы поведения различны в разных культурах.

К культурным детерминантам принятия экономических решений мы относим характеристики социокультурной среды, оказывающей влияние на личность и формирующей иерархию ценностей, нормы, обычаи, убеждения и верования, язык, этничность и другие аспекты личной и групповой идентичности.

Для понимания степени влияния культурных детерминант на процесс принятия экономических решений большое значение имеют эмпирические данные, показывающие, что разные люди и общества в целом систематически принимают разные экономические решения, сталкиваясь с решением одних и тех же хозяйственных проблем с одинаковым набором доступных альтернатив. Объяснить различия в процессе принятия экономических решений можно тем, что решения принимаются людьми, принадлежащими к разным культурам, в разных обществах в связи с различными средами, историей и культурой. Так, например, в работах Р. Нисбетта отмечается наличие психологических различий между людьми «западной культуры» 
(страны Европы) и «восточной культуры» (Китай, Япония) [1]. По его мнению, механизмы, участвующие в принятии решений, отличаются у представителей этих двух групп. Если люди Запада ищут причину преимущественно аналитическими, абстрактными способами, проводя анализ объектов в отрыве от окружающей их среды, то на Востоке, люди, как правило, ищут причину в комплексе, во взаимосвязи объектов друг с другом и с окружающей средой. Анализ различных культурных традиций, в значительной степени обусловленных религиозными, философскими, историческими особенностями, показывает, что западная традиция основана на прагматизме, определении наиболее существенного из наблюдаемых феноменов и его анализе, ориентирована на индивидуализм в принятии решений, в том числе экономических. Восточная традиция - предполагает принятие решения, основываясь на оценке взаимосвязей всех причин, обусловивших решение, ориентирована преимущественно на групповое взаимодействие, конформизм и сотрудничество.

Религия как составляющая культуры является значимым фактором, определяющим поведение человека (группы лиц) в процессе принятия решений и, как следствие, в воздействии на траектории долгосрочного развития. Религиозные традиции имеют достаточно сильное влияние на экономическое поведение людей. Целый ряд исследований показывает, что, принимая экономические решения, люди часто руководствуются религиозными нормами (М. Вебер, Я. М. Миркин, М. И. Гельвановский, А. Ю. Журавлев и др.). Так, например, Коран запрещает азартные игры, ссуды, спекуляцию, в результате чего целый ряд направлений современной хозяйственной деятельности становится неприемлемым для людей, следующим традициям ислама, во всяком случае, в явном виде. Исламская традиция, например, «проявляет себя в форме исламских финансов как формы финансового рынка, основанной на соблюдении инвесторами запрета ислама на взимание процента» [2]. Согласно исламской традиции деньги не могут являться объектом купли-продажи и не имеют самостоятельной ценности, они лишь посредники в товаробмене. Как следствие создание банковской системы, основанной на специфической системе займов и совместного участия банка-партнёра и предприятия-заёмщика. Религиозный запрет на любые операции с еще не произведенными активами-пассивами, возможность манипуляции только имеющимися товарами и услугами, фактически означает отказ от современной биржевой торговли.

Доказательное обоснование влияния религии на социально-экономическое поведение людей можно найти в работах М. Вебера, утверждавшего, например, что протестантизм провозглашает достоинством человека трудолюбие и мирской аскетизм, в то время как католицизм - стремление к богатству [3]. Параллели между протестантским акцентом на мирском аскетизме и идеалом капиталистической рациональности позволили Веберу связать Реформацию и возникновение капитализма: религиозные убеждения стимулировали возникновение специфических для капитализма форм поведения в повседневной и хозяйственной жизни. Анализируя базовые культурно-исторические типы мировоззрения, М. Вебер сопоставил западный тип хозяйствования с индуистско-буддийским, и пришел к выводу, что буддистское мировоззрение препятствует развитию предпринимательской деятельности и оказывает отрицательное влияние на экономику.

Ряд исследователей (Тревор Линг, Д. Пфэннер, Я. Ингерсолл, Э. Шумахер) полагают, что М. Вебер заблуждался в своих принципиальных оценках буддизма и его выводы во многом абстрактны и далеки от реальной действительности. Так, например, Э. Ф. Шумахер, создатель концепции «буддийской экономики», сравнив подходы западных и буддийских экономистов к пониманию категорий хозяйственной жизни, пришел к выводу, что экономика, основанная на буддистском принципе уменьшения страданий, принщипиально отличается от западной экономики, основанной на принципах максимизации прибыли, культивирования потребностей и эгоистических интересов, инструментального использования окружающего мира. В основе буддийской экономической теории, по мнению Э. Шумахера, находится человек, а не рост ВНП и производства на душу населения [4]. Примером может служить современное Королевство Бутан, экономическим выбором которого является не рост ВНП, а рост валового национального счастья ${ }^{2}$.

${ }^{2}$ Gross National Happiness Commission - Royal Government of Bhutan. URL: http://www.gnhc.gov.bt/en/ 
В любом случае, какой бы не была оценка влияния того или иного религиозного мировоззрения на экономическую систему, очевидно, что влияние религии на хозяйственную деятельность человека может быть столь значительным, что правомерно говорить о существовании «христианской», «исламской», «буддистской» экономик.

Культурные детерминанты принятия решений преимущественно относятся к процессу принятия эвристических решений, которые обычно проявляются в виде социальных норм, убеждений, ценностей и играют ключевую роль в процессе социально-экономического и исторического развития [5]. Так, например, согласно теоретическим моделям Бойда и Ричерсона, если издержки получения информации велики или процесс сбора информации несовершенен, использование эвристики или эмпирических правил в процессе принятия решений становится оптимальным [6]. Решение принимается, на основании имеющихся убеждений, ценностей, при этом лицо, принимающее решение не несет затрат на получение информации, необходимой для принятия оптимального решения, в этом случае польза от эвристических правил заключается в том, что они быстрее приносят выгоды, во многих средах перевешивающие некоторую их неточность.

Культурные детерминанты, как правило, инертны и это может способствовать отрицательному их воздействию на процесс и результат принятия экономических решений. Примером может служить возникновение, так называемой институциональной ловушки - неэффективной устойчивой нормы, имеющей самоподдерживающийся характер [7]. Неэффективность нормы проявляется в следовании устаревшим, хотя и привычным экономическим решениям, устойчивость определяется удобством, простотой следования привычной стратегии принятия экономических решений, а так же тем, что в случае отклонения от привычной стратегии поведения субъекты несут ощутимые потери. По мнению Д. Норта, возникновение институциональной ловушки означает, что в сложившихся условиях однажды принятое решение трудно отменить [8].

Принятие решения, в том числе экономического, как психологический процесс теснейшим образом связано с личностью, его совершающей. Безусловно, сложно проследить все личностные образования, в боль- шей или меньшей степени, тем или иным образом влияющие на то, какое конкретно экономическое решение примет человек или группа лиц. В любом случае, существуют компоненты структуры личности, помогающие принять решение, собирая воедино весь личный опыт, привычные для человека модели поведения, или же усложняющие процесс принятия решения. Такие структуры мы назовем личностными детерминантами стратегии принятия экономических решений. Личностные детерминанты стратегии принятия экономических решений представляют собой совокупность личностных качеств, оказывающих влияние на то, какие конкретно экономические решения и каким образом будут приняты. Системно-функциональный подход позволяет определить их как актуализирующиеся в условиях принятия решения личностные свойства. Личностные детерминанты стратегии принятия экономических решений имеют системное строение, включают причины, внутренние и внешние факторы, общие и специальные предпосылки, опосредующие звенья. Все личностные детерминанты стратегии принятия экономических решений находятся в определенном взаимодействии, оказывают влияние друг на друга, и в совокупности формируют единую структуру.

Личностные детерминанты стратегии принятия экономических решений определяются своеобразием психических процессов, состояний и качеств лица, разрабатывающего и принимающего решение, оказывающих влияние на процесс выбора и принятия решений. Условно их можно представить в виде трехуровневой системы, которая соответствует традиционной психической структуре личности (психические процессы, психические состояния, психические свойства):

1. Психические процессы - процессы, происходящие в психике человека и отражающиеся в динамически изменяющихся психических явлениях, таких, например, как ощущение, восприятие, память, мышление, речь, мотивация, эмоции и т. д. Так, например, мотивационные процессы предопределяют направленность, интересы, предпочтения, притязания личности, воздействуют на формирование целей деятельности человека или группы лиц и оказывают значительное влияние на процесс принятия решений;

2. Психическое состояние - целостная реакция личности на внешние и внутренние 
стимулы, направленная на достижение полезного результата, характеризует содержание психики человека, в различные моменты и периоды времени. Процесс принятие решений (способ и качество принимаемого решения) во многом определяется тем психическим состоянием, в котором находится лицо, принимающее решение. Так, например, А. Н. Леонтьев полагает, что одним из основных факторов, оказывающих влияние на процесс принятия решения в экстремальных условиях, является психическое состояние, человека, который принимает решение. Психическое состояние человека, принимающего решение, зависит как от конкретной ситуации, в которой находится человек, так и от его индивидуальных психологических особенностей.

3. Психические свойства - это устойчивые, постоянно проявляющиеся характеристики личности, которые обусловливают особенности ее поведения и деятельности: общие (наиболее типичные и фундаментальные особенности психики, присущие всем людям) и индивидуальные (конкретные формы, степень проявления и качественное своеобразие общих характеристик личности).

В структуре психических и в первую очередь индивидуальных свойств человека наибольшее влияние на процесс принятия решений оказывает личность, в частности, система предпочтений и уровень притязаний. Система предпочтений - это совокупность взглядов, ценностей, убеждений, интересов, с помощью которых лицом, принимающим решение, осуществляется сравнение альтернатив и принятие решения. Система предпочтений каждого человека уникальна, она формируется под влиянием воспитания, обучения, жизненного опыта человека, индивидуальных психических свойств личности. Не существует двух абсолютно идентичных систем предпочтений, поэтому возможно лишь в большей или меньшей степени приближение индивидуальных предпочтений людей, но не полное их совпадение, как следствие - несовпадение интересов и возникновение конфликтов. Кроме того, следствием несовпадения индивидуальных предпочтений является невозможность существования механизма принятия решения, удовлетворяющего в равной степени предпочтениям (интересам) всех участников выбора. Так, например, теорема «о невозможности» К. Эрроу доказывает, что не существует правила ра- ционального коллективного выбора, которое было бы одновременно универсальным, отвечало принципу Парето эффективности, не зависело от посторонних альтернатив и при этом предполагало бы действительно коллективное решение, не сводящееся к фиксации предпочтений одного индивида.

Уровень притязаний личности характеризует стремление человека к достижению целей той степени сложности, на которую он сам считает себя способным, не является врожденной характеристикой, формируется под влиянием предпочтений, способностей, опыта и переживаний личных достижений как успешных или не успешных. В процессе принятия экономических решения уровень притязаний влияет на формирование цели деятельности и выбор альтернатив, в большей степени соответствующих этим целям. Таким образом, к личностным детерминантам принятия решений следует отнести потребности, мотивы, ценностные ориентации личности. По мнению, Л. В. Папшева и Е. А. Грищенко мотивы, потребности, ценности детерминируют проявления личности и оказывают влияние на процесс выбора и принятия решения [9].

Потребность - нужда в чем-либо. 3. Фрейд определял потребность как влечение человека к определенному объекту, по мнению А. Н. Леонтьева потребность есть объективная нужда организма в чем-то внешнем - предмете потребности. Отсутствие блага, по мнению Е. П. Ильина, влечение, нехватка чего-либо направляет действие личности, причинно обусловливает поведение человека.

Мотив - это побуждение к активности, причина определенного поведения или поступка. Мотивация - это внутренняя детерминация поведения и деятельности, обусловленная внешними раздражителями, окружающей человека средой, при этом внешняя среда воздействует на человека физически, в то время как мотивация - процесс психический, преобразовывающий внешние воздействия во внутреннее побуждение. Исследование мотивации при разных типах принятия решений представлено в работах Т. В. Корниловой, О. В. Степаносова, М. А. Чумакова.

Важное место в структуре личности занимает система ценностей человека. Ценностные ориентации как система предпочтений образованы иерархией преобладающих цен- 
ностей. Ценности можно рассматривать как элементы или явления жизни общества, анализируемые с точки зрения того социального значения, которое им придается обществом в целом или отдельной социальной группой [10]. Кроме этого среди личностных факторов, осуществления выбора и принятия решения, исследователи выделяют: социальную креативность (Голованова, 2011) и творческие способности в целом (Исаев, Кормакова, 2008); индивидуальную религиозность (Знаков, 2010); особенности эмоциональной сферы (Сунцова, 2011); эмоциональный интеллект (Emmerling, Cherniss, 2003; Корнилова, Новотоцкая-Власова, 2009). Согласно исследователям С. Я. Уваровой и Т. Д. Дубовицкой (2010), умение принимать решения положительно связано с жизнестойкостью, осмысленностью жизни, общительностью и отрицательно - с подозрительностью и напряженностью.

Исследуя процесс выбора, Д. А. Леонтьев предлагает ввести индивидуально-психологическую переменную «готовность к выбору» - «комплексную индивидуально-психологическую характеристику личности, отражающую ее способность делать значимые выборы осознанно, самостоятельно, с осмыслением возможных последствий и принятием на себя ответственности и риска» [11]. Высказывается предположение, что готовность к выбору подвержена изменениям в ходе индивидуального развития, напрямую связана со становлением личностного потенциала, выступая в качестве интегральной характеристики одной из его подсистем потенциала самоопределения. Личностный потенциал - это «системная организация личностных структур, отвечающих за успешную саморегуляцию отношений личности с миром, включая ориентацию в пространстве возможных целей, успешную реализацию намеченного и сохранение устойчивости в условиях внешних давлений и других неблагоприятных обстоятельств» [12].

К теориям, акцентирующим внимание на роли личностных образований при выборе и принятии решений можно отнести следующие подходы:

1. Мотивационный подход - Мотивационная составляющая процесса принятия решений рассматривается не только в рамках теории деятельности, но таких теорий как: теория поля К. Левина - исследуется мотивационно обусловленная привлекательность результатов действий и условий, в которых возможно осуществление принятия решения (выбор может осуществляться только при неполевом поведении, когда сама личность включается в процесс принятия решений); теория когнитивного диссонанса Л. Фестингера - исследуются последствия принятия решений, включая переоценку самого решения; А. М. Айламазян, говоря о важности мотивационной сферы, делает акцент на внутреннем процессе выбора мотива деятельности, не ограничивая его лишь сознательными и произвольными процессами, предполагает наличие «надмотивационных» процессов. На основании результатов эксперимента с деловыми играми, приходит к выводу о том, что при реализации определенного поведения происходит учет смысловой сферы личности, ориентировка в собственных мотивах, ценностях и возможностях, это образует динамическую систему взаимосвязанных и взаимообусловленных элементов [13].

2. Волюнтаристский подход - выбор рассматривается выбор как этап процесса принятия решений, а не как отдельную самостоятельную активность (Ю. Куль, Л. Фестингер, Х. Хекхаузен). Больше внимание уделяется волевым процессам реализации решения, а не самому процессу принятия решений. По мнению В. А. Иванникова, борьба мотивов может быть частным случаем основы волевого действия, но выбор конкретного мотива необязательно связан с волей, он может осуществляться при достаточной силе одного из мотивов [14].

3. Эсхатологический подход - выбор, принятие решений рассматривается как результат свободного самоопределения личности, которое нельзя вывести ни из среды, ни из природы (М. К. Мамардашвили, С. Л. Рубинштейн).

4. Экзистенциальный подход - выбор рассматривается как результат активности личности, ее самоопределение относительно личностных ценностей, в основе выбора (принятия решения) лежит система ценностей, лица, принимающего решения,

Исследователи выделяют различные личностные детерминанты, влияющие на процесс принятия решений, вместе с тем, каждый автор акцентирует внимание на какой-то одной личностной детерминанте или группе детерминант, при этом отсутствует единая теория, раскрывающая влияние личностных детерминант на процесс принятия решений. 
Таким образом, можно сделать вывод, что развитие общества, в том числе, социально-экономическое, в значительной мере обусловлено культурными и личностными детерминантами, понимаемыми в широком смысле и включающими накопленный на различных этапах исторического развития соответствующий опыт (индивидуальный и коллективный), доминирующие в обществе мировоззрение, в том числе религиозное, поведенческие установки, ценностные убеждения. Культурные и личностные детерминанты стратегии принятия экономических решений находятся в определенной взаимосвязи и взаимодействии, влияют друг на друга, и в совокупности формируют единую структуру. При этом влияние культурных и личностных детерминант на характер и результат процесса принятия решений может быть как положительным, так и отрицательным.

\section{Список использованной литературы}

1. Nisbett Richard E. The geography of thought: how asians and westerners think differently and why / Richard E. Nisbett. - New York : The Free Press, 2003. - 263 p.

2. Миркин Я. М. Российский рынок ценных бумаг: влияние фундаментальных факторов, приоритеты и механизм развития : дис. ... Д-ра экон. наук / Я. М. Миркин. - М., 2003. 575 c. 352 c.

3. Вебер М. Протестантская этика и дух капитализма / М. Вебер. - М. : Ист-Вью, 2002. -

4. Шумахер Э. Малое прекрасно: экономика, в которой люди имеют значение / Э. Шумахер / / Экономическая социология. - 2012. - № 1. - С. 38-45.

5. Фиапшев А. Б. Культура как источник исторического процесса и фактор экономического развития / А. Б. Фиапшев, Л. М. Циканова, А. А. Фиапшева / / Национальные интересы: приоритеты и безопасность. - 2014. - № 11 - С. 45-50.

6. Boyd R. The origin and evolution of cultures / R. Boyd, P. J. Richerson. - New York : Oxford University Press, 2005. - 446 p.

7. Полтерович В. М. Институциональные ловушки и экономические реформы / В. М. Полтерович. - М. : Российская экономическая школа, 1998. - 42 с.

8. Норт Д. Институты, институциональные изменения и функционирование экономики / Д. Норт. - М. : Начала, 1997. - 180 с.

9. Папшева Л. В. Личностные детерминанты процесса принятия решения в ситуации морально-нравственного выбора / Л. В. Папшева, Е. А. Грищенко // Известия Саратовского университета. Новая серия. Серия Акмеология образования. Психология развития. 2010. - № 3. - C. 62-68.

10. Немов Р. С. Психология: словарь-справочник. В 2 ч. / Р. С. Немов. - М. : ВЛАДОСПРЕСС, 2003. - Ч. 2. - 352 с.

11. Личностный потенциал в ситуации неопределенности и выбора / / Личностный потенциал: структура и диагностика / Д. А. Леонтьев [и др.] ; под ред. Д. А. Леонтьева. - М. : Смысл, 2011. - С. 511-546.

12. Леонтьев Д. А. Психология выбора. Часть ІІ. Личностные предпосылки и личностные последствия выбора / Д. А. Леонтьев // Психологический журнал. - 2014. - Т. 35, № 6. С. 56-68.

13. Айламазян А. М. Выбор мотивов деятельности: теоретические аспекты проблемы и экспериментальное изучение / А. М. Айламазян / / Вопросы психологии. - 1990. - № 4. C. $123-130$.

14. Иванников В. А. Психологические механизмы волевой регуляции / В. А. Иванников. - СПб. : Питер, 2006. - 204 с.

\section{References}

1. Nisbett Richard E. The geography of thought: how asians and westerners think differently and why. New York, The Free Press, 2003. 263 p

2. Mirkin Y. M. Rossijskij rynok cennyh bumag: vlijanie fundamental'nyh faktorov, prioritety i mehanizm razvitij. Dr. Diss. [Russian securities market: influence of fundamental factors, priorities and mechanism of development. Dr. Diss.]. Moscow, 2003. 575 p.

3. Weber M. Protestantskaja jetika i duh kapitalizma [Protestant ethic and the spirit of capitalism]. Moscow, East view Publ., 2002. 352 p.

4. Schumacher E. Small is beautiful: economy where people matter. Ekonomicheskaya sotsiologiya = Economic sociology, 2012, no. 1, pp. 38-45. (In Russian). 
5. Fiapshev A. B., Chikanova L. M., Fiapsheva A. A. Culture as a source of historical process and a factor of economic development. Natsional'nye interesy: prioritety $i$ bezopasnost' = National interests: priorities and security, 2014, no. 11, pp. 45-50. (In Russian).

6. Boyd R., Richerson P. J. The origin and evolution of cultures. New York, Oxford University Press, 2005. 446 p.

7. Polterovich V. M. Institucional'nye lovushki i jekonomicheskie reformy [Institutional traps and economic reforms]. Moscow, Novaya Economicheskaya Shkola Publ., 1998. 42 p.

8. Nort D. Instituty, institucional'nye izmenenija i funkcionirovanie jekonomiki [Institutions, institutional change and economic performance]. Moscow, Nachala Publ., 1997. 180 p.

9. Papsheva L. V., Grishchenko E. A. Personal determinants of the decision-making process in a situation of moral choice. Izvestiya Saratovskogo universiteta. Novaya seriya. Seriya Akmeologiya obrazovaniya. Psikhologiya razvitiya = Saratov University Bulletin, New series. Series Acmeology of education . Developmental and educational psychology. 2010. No. 3, pp. 62-68.

10. Nemov R. S. Psihologija: slovar'-spravochnik [Psychology: dictionary]. Moscow, VLADOSPRESS Publ., 2003, Part 2. 352 p.

11. Leontiev D. A., Mandrikova E. Yu., Rasskazova E. I., Pham A. H. Personal potential in a situation of uncertainty and choice. In Leontiev D. A. (ed.). Lichnostnyi potentsial: struktura i diagnostika [Personality potential: structure and diagnostics]. Moscow, Znanie Publ., 2011, pp. 511-546.

12. Leontiev D. A. Psychology of choice. Part II. Personal background and personal implications of the selection. Psikhologicheskii zhurnal = Psychological journal, 2014, vol. 35, no. 6. - pp. 56-68. (In Russian).

13. Aylamazyan A. M. The choice of motives of activity: theoretical aspects and experimental study. Voprosy psikhologii = Questions of psychology, 1990, no. 4, pp. 123-130. (In Russian).

14. Ivannikov V. A. Psihologicheskie mehanizmy volevoj reguljacii [Psychological mechanisms of volitional regulation]. Saint Petersburg, Piter Publ., 2006. 204 p.

\section{Информация об авторе}

Шавкунова Ирина Сергеевна - кандидат экономических наук, доцент, кафедра экономической теории и институциональной экономики, Байкальский государственный университет, 664003, г. Иркутск, ул. Ленина, 11, e-mail: shavkunovais@mail.ru.

\section{Для цитирования}

Шавкунова И. С. Культурные и личностные детерминанты стратегии принятия экономических решений / И. С. Шавкунова // Психология в экономике и управлении. - 2017. - Т. 9, № 2. C. 18-25. - DOI: 10.17150/2225-7845.2017.9(2).18-25.

\section{Author}

Irina S. Shavkunova - PhD in Economics, Associate Professor, Department of Economic Theory and Institutional Economics, Baikal State University, 11 Lenin St., 664003, Irkutsk, the Russian Federation; e-mail: shavkunovais@mail.ru.

\section{For Citation}

Shavkunova I. S. Cultural and personal determinants of economic decisions-making strategy. Psikhologiya $v$ ekonomike $i$ upravlenii $=$ Psychology in Economics and Management, 2017, vol. 9, no. 2, pp. 18-25. DOI: 10.17150/2225-7845.2017.9(2).18-25. (In Russian). 